\title{
Resource accounting in factories and the energy-water nexus
}

\author{
Sanober Hassan Khattak ${ }^{1} \cdot$ Richard Greenough $^{1}$
}

Received: 21 March 2017 / Accepted: 11 September 2017 /Published online: 11 October 2017

(C) The Author(s) 2017. This article is an open access publication

\begin{abstract}
A manufacturing system comprises production processes and building services, both of which are supplied by different energy carriers as well as raw materials and water. These resources interact according to complex relationships and are converted into products for sale and waste flows. Holistic resource accounting allows the analyst to consider the dynamic relationships between these components, including the strong interdependence between energy and water, which has been called the energy-water nexus. Exergy analysis is a method that accounts for mass and both the quantity and quality of energy, while allowing analysis on a common basis, and for this reason, it is used increasingly to analyse resource consumption in manufacturing systems; however, it has rarely been used to consider water flows alongside energy and material flows. The main contribution of this paper is the presentation of modelling water flows in terms of exergy in the context of sustainable manufacturing. Using this technique in combination with previously developed exergy-based methods, the result is a truly holistic resource accounting method for factories based on exergy analysis that incorporates water flows. The method is illustrated using a case study of a food factory in which a $4.1 \%$ reduction in resource use is shown to be possible by employing anaerobic digester in an effluent water treatment process. The benefits of this technology option
\end{abstract}

Sanober Hassan Khattak

skhattak@dmu.ac.uk; san.uni@hotmail.com

Richard Greenough

rgreenough@dmu.ac.uk

Institute of Energy and Sustainable Development (IESD), De Montfort University, Queens Building, The Gateway, Leicester LE1 9BH, UK would have been underestimated compared to the benefits of waste heat capture if an analysis based on mass and energy balances alone had been used. The scientific value of this paper is the demonstration of the relatively high exergy content of effluent flows, which should therefore be regarded as potentially valuable resources. The analytical method presented is therefore of value to a wide range of industries beyond the food industry.

Keywords Resource accounting in factories · Exergy analysis $\cdot$ Energy-water nexus $\cdot$ Resource efficiency . Sustainable manufacturing $\cdot$ Energy efficiency

$\begin{array}{ll}\begin{array}{l}\text { Abbreviations } \\ b\end{array} & \text { Specific exergy } \\ b c h & \text { Specific chemical exergy } \\ h_{0} & \text { Specific enthalpy at reference environment } \\ & \text { conditions } \\ C_{0} & \text { Concentration of Substance k in the mixture at } \\ & \text { reference environment conditions } \\ C_{k} & \text { Concentration of Substance k in the mixture } \\ T_{0} & \text { Temperature at reference environment } \\ V & \text { conditions } \\ a_{A} & \text { Velocity } \\ a_{B} & \text { Activity of reactant substance ' } A \text { ' } \\ a_{C} & \text { Activity of reactant substance ' } B \text { ' } \\ c_{p} & \text { Activity of reactant substance ' } C \\ e x_{\text {chem }} j & \text { Specific heat capacity } \\ e x_{\text {concentration }} & \text { Specific Standard Chemical Exergy of sub- } \\ e x_{\text {formation }} & \text { Stance ' } j \text { ' in a mixture } \\ e x_{\text {kinetic }} & \text { Specific concentration chemical exergy } \\ e x_{\text {potential }} & \text { Specific kinetic exergy }\end{array}$




$\begin{array}{ll}e x_{\text {thermo- }} & \text { Specific thermo-mechanical exergy } \\ \text { mechanical } & \\ e x_{\text {total }} & \text { Total specific chemical exergy } \\ p_{0} & \text { Pressure at reference environment conditions } \\ x_{k} & \text { Molar fraction of substance } k \\ y_{i} & \text { Molar fraction of substance ' } i \text { ' } \\ \Delta G^{0} & \text { Gibbs free energy at standard conditions } \\ \mathrm{a} & \text { Chemical activity } \\ \mathrm{A} & \text { General reactant substance 'A' } \\ \mathrm{AD} & \text { Anaerobic digestion } \\ \mathrm{AFMBR} & \text { Anaerobic fluidized bed bioreactor } \\ \mathrm{B} & \text { General reactant substance 'B' } \\ \mathrm{C} & \text { General product substance 'C' } \\ \mathrm{CExC} & \text { Cumulative exergy consumption } \\ \mathrm{CIP} & \text { Clean-in-place } \\ \mathrm{COD} & \text { Chemical oxygen demand } \\ \mathrm{EU} & \text { European Union } \\ h & \text { Specific enthalpy } \\ \mathrm{OM} & \text { Organic matter } \\ \mathrm{RE} & \text { Reference environment } \\ \text { TOC } & \text { Total organic content } \\ \mathrm{X} & \text { Moles of substance 'A' } \\ \mathrm{Y} & \text { Moles of substance 'B' } \\ \mathrm{Z} & \text { Moles of substance 'C' } \\ \Delta \mathrm{G} & \text { Change in Gibbs free energy } \\ G & \text { Gibbs free energy } \\ H & \text { Enthalpy } \\ R & \text { Universal gas constant } \\ S & \text { Entropy } \\ T & \text { Temperature } \\ g & \text { Specific Gibbs free energy } \\ n & \text { Amount of substance in moles } \\ p & \text { Pressure } \\ v & \text { Specific volume } \\ & \end{array}$

\section{Introduction}

The manufacturing of goods and services in factory environments involves a complex interaction between energy, material and water resources. An example is that of a cooling tower where water is used to extract thermal energy, an energywater interaction. Therefore, resource analysis techniques should be able to account for such exchanges between resources of varied nature, allowing a holistic assessment of the manufacturing environment. A clear need to understand multiple resources concurrently, on a common scale, has been identified by researchers over the past decade [1-3]. This holistic perspective of the factory is underpinned by the premise that its components interact dynamically. The main advantage of using a holistic perspective is that it avoids sub-optimal solutions. Schlüter and Rosano [4] assessed the energy efficiency improvement measures at a plastic-processing factory using a holistic approach. The study estimated energy savings at two plastic-processing plants, in which a number of energy efficiency measures were analysed. The impact of the efficiency measures, when installed in the factories separately without taking a holistic perspective, was measured. This was followed by an assessment of the same interventions using a holistic perspective. The resulting reductions in primary energy demand by combining the measures separately were 26 and $20 \%$. However, when the energy-saving measures were combined using a holistic approach, significantly greater reductions of 41 and $43 \%$ were observed, thus emphasising the advantages of a holistic approach. Other studies have arrived at similar conclusions further demonstrating the benefits of holistic approaches for factory analysis [3, 5, 6]. A review of the latest literature does not show any signs of a change in this trend [7]; therefore, holistic approaches for factory resource analysis can be considered the way forward for sustainable manufacturing.

Water resource consumption has increased twice as fast as the population growth over the past century and is predicted to increase by a further $18 \%$ in the EU by 2025 [8]. According to the World Business Council for Sustainable Development, in $60 \%$ of the European cities with more than 100,000 inhabitants, groundwater is being used at a faster rate than it can be replenished [9]. Industry is a significant consumer of water, with energy generation and food processing being the main sectors responsible [10]. The consumption of energy and water is often interdependent, a concept that is termed as the 'energy-water nexus'. Energy is used for water extraction, purification, packaging, transportation and wastewater treatment. Conversely, water is used in production processes and building services in factories. For example, food processing factories need to adhere to strict clean-in-place (CIP) hygiene standards that are waterintensive processes [11-13]. With the increasing importance of water efficiency in manufacturing, there is a need for resource accounting methods for factories that can analyse flows of water in addition to flows of energy and material [3].

\section{Exergy-based resource accounting in manufacturing}

Studies have recently been conducted that included water alongside energy and material flows. Thiede et al. [3] presented an energy-based holistic simulation approach to manufacturing companies, with a specific focus on the interdependence between energy and water (the energy-water nexus). In terms of modelling water flows, the scope of this study was limited since it was based on the first law of thermodynamics and only the thermal energy content of water was considered, without any consideration of water quality. Mousavi et al. [14] also developed a modelling approach based on the first law of thermodynamics, for the simultaneous assessment of energy and water resources at a factory, 
but the consumption of quality water as a resource was not considered. Hernandez and Cullen [15] argue that the first law-based efficiency metrics are not suitable for holistic analysis approaches because such methods do not allow an objective comparison between the use of resources of a varied nature. For this reason, exergy, a concept based on the second law of thermodynamics, has been widely used to assess and identify the locations of resource losses in production facilities. Leung Pah Hang et al., [16] presented an exergy-based resource accounting methodology for local food processing systems. Their study considered the interaction between energy and water flows and strived to achieve an integrated design solution. Though material and water were not modelled in terms of exergy, the effect of all energy-material-water synergies was measured through cumulative exergy consumption (CExC). To assess the 'quality' and energy recovery potential of water flows, the parameter chemical oxygen demand (COD) was used. However, no means of tackling the presence of inorganic impurities in water was presented. In another example, Garcia et al., [17] used a simulation and exergybased approach for simultaneous assessment of varied resource flows; however, only the thermal exergy content of water flows was taken into account. While current literature is increasingly focused on holistic analysis of manufacturing systems, it remains the case that clean water as a resource is rarely analysed using the same tools as energy and material.

This paper proposes to a method for modelling the water flows in a factory environment in terms of chemical exergy, to address the problem of increasingly strained global clean water resources. The remainder of Section 2 describes how the exergy concept has been used to model water flows in general, culminating in the research question that is addressed in this paper (Section 2.2). A central objective of this paper is to present the methodology for explicitly modelling water flows in a factory environment using the exergy concept presented in Section 3. The use of the methodology is illustrated with a case study based on an analysis of effluent water from a food processing factory (Section 4).

\subsection{Exergy modelling of water flows}

Exergy, a property of a system and its surroundings based on the second law of thermodynamics, has increasingly been adopted to analyse the losses and inefficiencies in manufacturing systems $[18,19]$. The exergy concept allows the use of water, material and energy resources to be quantified on a common basis. As resources flows through manufacturing systems, their quantity is conserved but they degrade in quality. This degradation results in exergy destruction which has been used as a measure of resource consumption [20]. For this reason, studies in literature can be found in which resource accounting analyses the destruction of exergy in manufacturing processes. For example, Nguyen et al., [21] presented a comparison of analysis techniques for a milk-processing facility, with the goal of identifying inefficiencies and improvement potentials in the production line. The study showed that exergy analysis proved useful compared to pinch analysis for identifying the components with the highest losses, but that it required additional data. While water flows in the production line were modelled, only the thermal exergy content was considered, neglecting the influence of water quality on exergy. Similarly, Soufiyan et al., [22] and Jokandan et al., [23] presented comprehensive exergy analyses of a commercial tomato paste plant and a yogurt production plant. In both these studies, the physical exergy content of water flows was considered but not the chemical exergy content, thus neglecting issues of water quality. Zisopoulos et al., [24] compared the exergetic performance of three bread production chains that involved the concepts of waste minimization and reuse. Even though the study had a strong chemical exergy focus, since it is the dominant type of exergy content for such processes, only the physical exergy of water flows was considered. Other similar examples can be found in review articles documenting the use of exergy analysis for industrial processes, with a small number of studies that consider water alongside energy and material [25-27]. To date, the studies that have taken into account issues of water quality and its chemical exergy content have either been specifically about wastewater treatment or resource accounting of natural water bodies such as lakes and rivers.

One of the earliest studies that used the exergy concept to quantify resource consumption in wastewater treatment was by Hellström [28]. The study showed the strengths and limitations of exergy analysis compared with energy analysis. The results showed that energy analysis overestimated the value of the waste heat in the effluent water, which is because energy analysis disregards the quality aspect of energy. On the other hand, Hellström found that exergy analysis underestimated the decrease in phosphorous resources as well as being unsuitable for measuring toxicity. He concluded that exergy analysis was an imperfect but 'greatly improved' tool compared to energy analysis for the purposes of quantifying physical resource consumption in water treatment.

Balkema et al. [29] attempted to measure the environmental sustainability of a water treatment process by calculating its exergy efficiency, but as with the earlier study by Hellström, the inability of exergy to account for toxicity was its major weakness in this context [30]. Other researchers such as Ao et al. [31] and Gaudreau et al. [32] also arrived at similar conclusions concerning this weakness of the exergy concept for modelling water flows. Calculations of exergy alone are therefore insufficient to quantify environmental impact of wastewater flows. Nonetheless, exergy can be considered a more useful indicator compared to either mass or energy, especially when focusing on resource consumption rather than environmental impact. Considering the strengths rather than the limitations of exergy analysis in this context, Mora and 
Oliveira [33] used exergy efficiency to evaluate the resource consumption in two wastewater treatment plants. The byproducts of wastewater treatment are methane gas and sludge cake (used as a fertiliser), which can be used to offset the exergy requirements of the process. Seckin and Bayulken [34] calculated the exergy required to treat municipal wastewater for the Turkish household sector. The treatment process used was anaerobic digestion, which is suitable for treating water effluent with high organic content. The majority of literature on exergy modelling of model water flows has been applied to natural water bodies and urban wastewater treatment [35]. Since current research on resource accounting in manufacturing advocates a holistic analysis, modelling the factory flows of water in addition to energy and material on a common basis, through the concept of exergy should facilitate this goal.

\subsection{Research question}

It is clear that while researchers advocate techniques that can analyse material, energy and water resources in a holistic way, the interaction between these three resources has generally not taken sufficient account of water quality. The objective of this paper is therefore to present the method for water quality in a factory environment, as part of the broader methodology that uses exergy to tackle holistically the issue of resource accounting in factories. The literature review can be summarised along the following four lines of investigation:

1. A search for studies of factory resource flows that avoid the creation of sub-optimal solutions by considering the factory to be an integrated system comprising production processes, building services and the building fabric.

2. A review of studies in which water flow is considered alongside flows of energy and material, whilst taking into consideration the energy-water nexus.

3. A review of studies in which exergy analysis is used to account for resource consumption in environmental science in general and, specifically, for manufacturing systems analysis.

4. A review of studies using exergy to quantify water quality, whether in a water treatment context or a manufacturing context.

Based on the literature review presented, the following research questions are defined:

1. How can water flows in a factory environment be modelled in terms of exergy to facilitate the analysis of energy, material and water flows on a common unit basis?

2. Would this facilitate a holistic approach to factory resource accounting, whilst considering the close linkage between energy and water demand (the energy-water nexus)?

The main objective and contribution of this article is to demonstrate the modelling of water flows using exergy, with the goal of enabling the comparison of technology options that affect consumption of resources at a factory. The specific objectives of the study are as follows:

1. To present the methodology for calculating the exergy content of water flows in a factory environment whilst taking into account its quality and composition

2. To illustrate the method with a case study of a food processing facility that compares existing resource consumption with consumption under a hypothetical water treatment scenario, in order to quantify the impact of water treatment on resource consumption

\section{Methodology}

Since exergy is a property of not only the system but also of the surroundings, selection of the exergy reference environment (RE) is especially critical and is described first.

\subsection{Reference environment selection for water}

The reference environment (RE) with respect to water has to represent the 'dead state', so its makeup should approximate the composition of water that represents zero potential to cause change and is found most abundantly on earth. As a result, any variation in composition of a water sample from this reference 'dead state' results in positive values of exergy. Martínez and Uche [36] provide a discussion on the most suitable choice for reference water composition. Reasonable choices are pure water, spring water and seawater. While each choice has its advantages, the majority of studies in literature use seawater, mainly for the reason that it is the most abundant and stable composition of water present on earth. Examples of pioneering work in this field which have used this choice of RE are those of Szargut et al. [37] and Valero et al. [38]. Within the choice of seawater, there is the option of considering organic content as part of it. When organic matter is considered part of reference seawater, the concentration exergy formula uses a natural logarithmic function that underestimates the work potential of the organic matter in a water sample. Fig. 1 illustrates this limitation by plotting the increase of exergy in response to increasing total organic content (TOC). If the RE uses seawater that includes organic content, there is an insufficient increase in the specific exergy relating to the organic content so that this is not a true representation of its work potential. This limitation is not present if the RE uses 


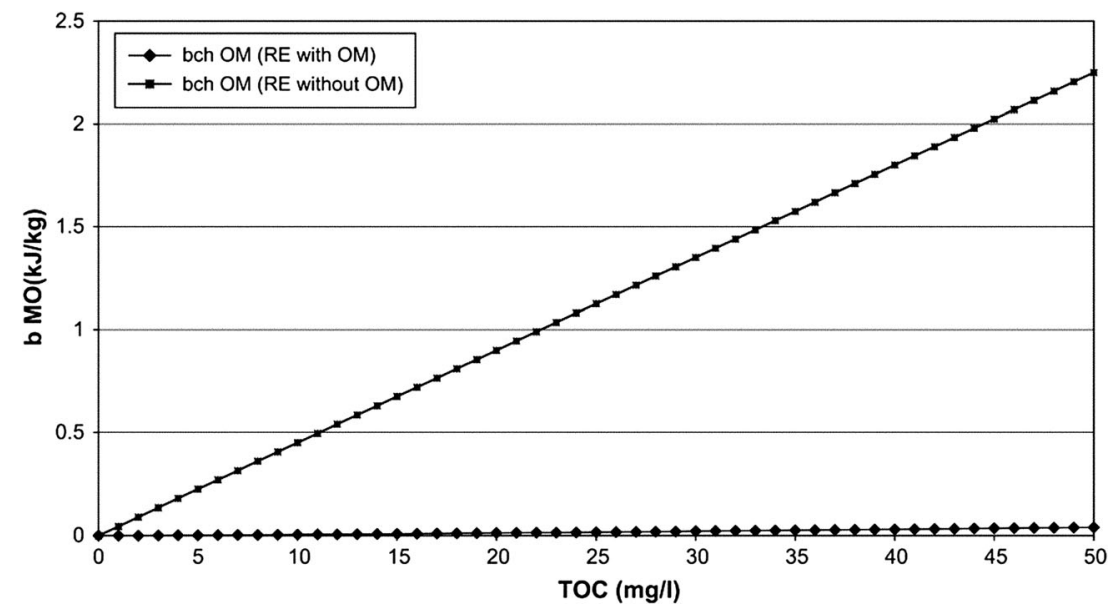

Fig. 1 Effect on specific exergy due to consideration of total organic content in the RE seawater [39]

seawater without organic content, therefore, seawater without organic content is chosen as the RE water in this paper.

\subsection{Exergy of water flows}

The total exergy of a mass flow in general is comprised of five parts as given in Eq. 1 [40],

$$
\begin{aligned}
e x_{\text {total }}= & e x_{\text {thermo-mechanical }}+e x_{\text {formation }}+e x_{\text {concentration }} \\
& + \text { ex } x_{\text {kinetic }}+e x_{\text {potential }}
\end{aligned}
$$

\subsubsection{Thermo-mechanical exergy}

The thermo-mechanical exergy component is due to the temperature and pressure of the water flow. The thermal exergy component is calculated using the difference in temperature of the water sample and the reference environment. In the current study, the temperature of the water effluent was recorded using ultrasonic heat flow measurement equipment. The mechanical exergy component is calculated using the specific volume and the pressure differential that exists between the water sample and the RE. This exergy component is calculated using Eq. (2) as follows:

exthermo-mechanical $=c_{p}\left[T-T_{0}-T_{0} \ln \left(\frac{T}{T_{0}}\right)\right]+v\left(p-p_{0}\right)$

Typically, the effluent water is at atmospheric pressure resulting in zero mechanical exergy. The average temperature of the effluent water recorded over a work week was $T(302.95 \mathrm{~K})$. The RE temperature $T_{0}$ and the specific heat capacity of water $c_{p}$ used are $298.15 \mathrm{~K}$ and $4.2 \mathrm{~kJ} / \mathrm{kgK}$, respectively.

\subsubsection{Chemical exergy}

The major contribution towards the total exergy is due to its chemical component which depends on the composition as well as the concentration of the substances dissolved in the water. The chemical exergy is classified into two parts [41]:

1. Chemical formation exergy. This is calculated for organic substances that are not present in the RE water.

2. Concentration exergy. This is calculated for inorganic substances in the water sample that are already present in the RE water.

Chemical formation exergy (organics) For the selected RE water composition, no organic compounds are present, so their synthesis through appropriate chemical reactions must be considered. Chemical formation exergy is the minimum energy required to form the chemical substance using the elements present in the reference environment. It is calculated using the Gibbs free energy,

$G=H-T S$

where $G, T$ and $S$ are the Gibbs free energy, absolute temperature and entropy respectively. As a chemical reaction proceeds, the change in the Gibbs free energy, $\Delta \mathrm{G}$, can be thought of as the maximum work obtainable from the reaction, or the work output in an isothermal expansion. It can be calculated using Eq. (6), where the Gibbs free energy at standard conditions, $\Delta G^{0}$ is available in thermodynamic property tables such as Lide [42]. Let us consider a general reversible chemical reaction,

$x A+y B \leftrightarrow z C$

where $C$ is the product, $A$ and $B$ are the reactants. The 
coefficients $x, y$ and $z$ represent the amounts of each substance (in moles) based on the stoichiometric-balanced chemical reaction. It should be noted that in weak solutions, such as the water sample considered in this study, the activity $(a)$ is equal to the molarity (mol/l) [39]. Since $\Delta G$ represents the maximum work obtainable from the chemical reaction, it is by definition the chemical formation exergy [43] and is calculated by Eq. (6) as follows.

$e x_{\text {formation }}=\Delta G=\Delta G^{0}+R \operatorname{Rln}\left[\frac{a_{C}}{a_{A} a_{B}}\right]=\sum_{i} y_{i}\left[\Delta G^{0}+\sum n_{j} e x_{\text {chem }, j}\right]$

Where $R$ is the universal gas constant $(8.314 \mathrm{~J} / \mathrm{kgK}), T$ is the reference environment temperature $(298.15 \mathrm{~K}), a_{A}, a_{B}$ and $a_{C}$ are the activities of substances $\mathrm{A}, \mathrm{B}$ and $\mathrm{C}$ respectively. The standard chemical exergies of elements and common compounds $\left(e x_{c h e m}, j\right)$ have been tabulated by Szargut et al. [44] and can also be found in online databases such as the CIRCE Exergoecology Portal [45]. The exergy of the organic impurities present in the effluent water is calculated and summed according to their relative proportions in the water sample [46].

Applying Eq. (5) to the case of organic matter in water, a representative molecule needs to be chosen to approximate the organic content. The actual organic content will comprise a wide range of different chemical compounds, but the assumption of a 'mean organic substance' molecule needs to be made in order to calculate the chemical formation exergy. Different researchers have used different mean organic substances. For example, Armando et al. [41] used the fat molecule $\mathrm{C}_{39} \mathrm{H}_{80} \mathrm{O}_{3}$ resulting in the balanced chemical reaction,

$\mathrm{C}_{39} \mathrm{H}_{80} \mathrm{O}_{3}+57.5 \mathrm{O}_{2} \Leftrightarrow 39 \mathrm{CO}_{2}+40 \mathrm{H}_{2} \mathrm{O}$

This chemical reaction represents the oxidation of the organic molecule to form the products of the reaction. Other researchers have used $\mathrm{CH}_{2} \mathrm{O}$ (formaldehyde) as a typical organic molecule; the results obtained from using the two different representative organic substances were compared by Martínez and Uche (2010). An alternative method to the assumption of a mean organic substance was presented by Tai et al. [43]. The standard chemical exergy of 138 other organic compounds was listed through which a correlation between the COD (chemical oxygen demand) and specific chemical exergy was found (Eq. 8),

$\operatorname{ex}(\mathrm{J} / \mathrm{kg})=13.6 \times \operatorname{COD}(\mathrm{mg} / \mathrm{kg})$

Since the organic content dominates the total exergy content in the water sample, results are obtained and compared using all the three methods described (Table 2).

Chemical concentration exergy (inorganic part) For substances that are already present in the RE water, difference in the concentration in the water sample to that of the reference environment is used to calculate their theoretical work potential. Corresponding to the concentration of inorganic substances in the RE water, the standard chemical exergy of various chemical compounds were calculated by Szargut et al. [37] which have been updated by Rivero and Garfias [47]. By measuring the concentration of the inorganic compounds in the water sample, the chemical concentration exergy is calculated as follows [48]

$e x_{\text {concentration }}=R T_{0} \sum_{k} x_{k} \ln \left(\frac{C_{k}}{C_{0}}\right)$

Where $R$ is the universal gas constant $(8.314 \mathrm{~J} / \mathrm{mol} . \mathrm{K})$ and $T_{0}$ is the reference environment temperature $(288.15 \mathrm{~K}), x$ is the molar fraction and $C$ is the concentration.

\subsubsection{Kinetic and potential exergy}

This component is calculated in a similar way to kinetic and potential energy (see Eq. 3). However, its value is typically negligible compared to the chemical exergy [49].

$e_{\text {kinetic }}+e x_{\text {potential }}=\frac{1}{2}\left(\vec{V}^{2}-\vec{V}_{0}^{2}\right)+g\left(h-h_{0}\right)$

\subsubsection{The total exergy}

The total exergy for an incompressible substance can be calculated through Eq. (10) as

$$
\begin{aligned}
e x_{\text {total }}= & c_{p}\left[T-T_{0}-T_{0} \ln \left(\frac{T}{T_{0}}\right)\right]+v\left(p-p_{0}\right) \\
& +\sum_{i} y_{i}\left[\Delta G^{0}+\sum n_{j} \text { ex } x_{\text {chem }, j}\right] \\
& +R T_{0} \sum_{k} x_{k} \ln \left(\frac{C_{k}}{C_{0}}\right)+\frac{1}{2}\left(V^{2}-V_{0}^{2}\right)+g\left(h-h_{0}\right)
\end{aligned}
$$

where $n_{j}$ is the number of moles of the element in the compound, $e x_{c h e m}, j$ is the standard chemical exergy in the RE and $y_{i}$ is the molar fraction of the element in the compound. Typically, for water flows in manufacturing, the thermal and chemical exergy dominates the overall exergy. For food processing effluent water, it will be shown later that the main contribution to the exergy content is due to its chemical composition while other components can be neglected, resulting in the simplified Eq. (11),

$e x_{\text {total }}=\sum_{i} y_{i}\left[\Delta G^{0}+\sum n_{j} e x_{\text {chem }, j}\right]+R T_{0} \sum_{k} x_{k} \ln \left(\frac{C_{k}}{C_{0}}\right)$ 


\section{Case study}

This section uses the described methodology to evaluate a sample of effluent water from a food processing factory. The total energy and water consumption data for the facility were provided by the factory management. The weekly electricity, water and natural gas resource supplied to the factory are provided in Table 1 . The resource consumption figures for 2014 are based on actual data collected between January and March, which is the baseline resource consumption for the factory. For the effluent water, a heat meter was used to measure its flow rate and temperature. A sample of the effluent water was taken from an open flow channel just before drainage to the public sewage network. The chemical composition of the sample was analysed by a water quality test laboratory [50].

\subsection{Exergy of supply water}

The composition of supply water to the factory was acquired from the local supply water quality report [51]. Based on the composition, it is assumed to be pure water, composed of only the $\mathrm{H}_{2} \mathrm{O}$ molecule that has a specific chemical exergy of $41.67 \mathrm{~kJ} / \mathrm{kg}$ [45]. Additionally, the kinetic and potential exergy is typically negligible compared to the chemical exergy component [49]. Since water consumption of the food processing plant in 2014 was $3510 \mathrm{~m}^{3} /$ week or $5.8 \mathrm{~kg} / \mathrm{s}$, the total specific exergy of the supply water becomes $241.7 \mathrm{~kW}$ or $40,605 \mathrm{kWh} /$ week.

\subsection{Exergy of effluent water}

For the effluent water, an average mass flow rate of $4.55 \mathrm{~kg} / \mathrm{s}$ was recorded at a temperature of $28.9^{\circ} \mathrm{C}$. The chemical exergy of the effluent water sample was calculated based on the water quality data acquired from lab specimen analysis, see Table 2. Three methods to calculate the exergy content of organic compounds were used, and it can be seen that there is significant variation in the results obtained $(52.6-66.8 \mathrm{~kJ} / \mathrm{kg})$. The value of $52.6 \mathrm{~kJ} / \mathrm{kg}$, which was obtained using method 3 , was used for further analysis because the assumption of a representative organic molecule in methods 1 and 2 is rather

Table 1 Average weekly resource consumption at the food factory

\begin{tabular}{llll}
\hline Year & Gas $(\mathrm{kWh})$ & Electricity $(\mathrm{kWh})$ & Water $\left(\mathrm{m}^{3}\right)$ \\
\hline 2011 & 913,324 & & 3302 \\
2012 & 679,290 & 224,898 & 3335 \\
2013 & 728,257 & 224,351 & 3542 \\
$2014^{*}$ & 737,920 & 204,434 & 3510 \\
\hline
\end{tabular}

* Weekly average based on actual data collected from January to March subjective. Also, the relation obtained by Tai et al. [43] in method 3 is based on experimental data that holds true for a large number of organic compounds. Finally, method 3 offers a simple calculation method, which increases its practicality. Exergy content due to inorganics in the food effluent is orders of magnitude smaller than that due to the organic part. This is typical of a food processing factory as the raw material for production is largely organic in nature.

The negative signs resulting from the concentration of inorganic matter are meaningless and simply represent a variation from the reference and should only be thought of in terms of their magnitudes. Using their absolute values, the total specific exergy of the effluent water becomes $54.75 \mathrm{~kJ} / \mathrm{kg}$. For the average weekly mass flow rate of $4.55 \mathrm{~kg} / \mathrm{s}$, the chemical exergy rate of the effluent amounts to $248.9 \mathrm{~kW}$ or $41,815 \mathrm{kWh} /$ week. For the temperature of $302.95 \mathrm{~K}$, the specific thermal exergy content amounts to $0.073 \mathrm{~kW}$ or $12.36 \mathrm{kWh} /$ week. It is noteworthy here that the thermal exergy content is only $0.03 \%$ of the chemical exergy content and can be neglected in further analysis.

Figure 2 puts the specific exergy of effluent water in context by comparing it with five other water bodies in the world with the largest specific exergies. Food process effluent has a higher specific exergy than the Dead Sea and is 12.1 times greater than Spanish urban wastewater.

While the specific exergy values of the Dead Sea and food process effluent are comparable, they are different in nature. The source of the high exergy content in the Dead Sea water is the presence of inorganic compounds, whereas for the food process effluent it is organic compounds, which can be converted to useful products through appropriate water treatment processes. The high exergy content of the effluent water highlights the resource recovery potential, which could not have been possible using energy analysis. The next section considers a hypothetical anaerobic digestion process to treat and convert the organic matter in the effluent water to useful products. The overall impact on resource consumption is then quantified using the common basis of exergy.

\subsection{Using anaerobic digestion for resource recovery}

A common process used to recover energy from organic content in wastewater is the anaerobic digestion (AD) process. This is a biochemical process in which microorganisms in settling tanks digest and convert the organic matter in wastewater to methane gas $\left(\mathrm{CH}_{4}\right)$ and residue. The residue can be used as a substitute for fertiliser, and along with the gas, it is a valuable output from the treatment process. Mora and Oliveira [33] describe the stages of the AD process as filtration, digestion and chemical treatment. The supplied resources to the process are electricity and chemicals, typically resulting in organic content removal between $70-80 \%$. 
Table 2 Chemical test results and specific exergy calculation of the food process effluent sample

Inorganic matter

\begin{tabular}{|c|c|c|c|c|c|c|}
\hline Substance & $\begin{array}{l}\text { Test result } \\
(\mathrm{mg} / \mathrm{kg})\end{array}$ & $\begin{array}{l}\text { Molar mass } \\
(\mathrm{g} / \mathrm{mol})\end{array}$ & $\begin{array}{l}\text { Moles of substance } \\
\text { in sample } \\
(\mathrm{mol} / \mathrm{kg})\end{array}$ & Mole fraction & $\begin{array}{l}\text { molarity in RE } \\
(\mathrm{mol} / \mathrm{kg})\end{array}$ & $\begin{array}{l}\text { Exergy } \\
(\mathrm{kJ} / \mathrm{kg})\end{array}$ \\
\hline Chloride $(\mathrm{Cl})$ & 330 & 3.55 & $9.31 \mathrm{E}-03$ & $1.39 \mathrm{E}-04$ & $5.66 \mathrm{E}-01$ & $-1.37 \mathrm{E}-03$ \\
\hline Sulphate(SO4) & 1.5 & 9.61 & $1.56 \mathrm{E}-05$ & $2.34 \mathrm{E}-07$ & $1.17 \mathrm{E}-02$ & $-3.91 \mathrm{E}-06$ \\
\hline Calcium $(\mathrm{Ca})$ & 68 & 4.01 & $1.70 \mathrm{E}-03$ & $2.54 \mathrm{E}-05$ & $9.60 \mathrm{E}-03$ & $-1.06 \mathrm{E}-04$ \\
\hline Sodium(Na) & 340 & 2.30 & $1.48 \mathrm{E}-02$ & $2.21 \mathrm{E}-04$ & $4.74 \mathrm{E}-01$ & $7.85 \mathrm{E}-01$ \\
\hline Magnesium(Mg) & 16 & 2.43 & $6.58 \mathrm{E}-04$ & $9.85 \mathrm{E}-06$ & $4.96 \mathrm{E}-02$ & $2.87 \mathrm{E}-02$ \\
\hline Potassium(K) & 82 & 3.91 & $2.10 \mathrm{E}-03$ & $3.14 \mathrm{E}-08$ & $1.04 \mathrm{E}-02$ & $6.58 \mathrm{E}-01$ \\
\hline \multicolumn{7}{|l|}{ Organic matter } \\
\hline \multirow[t]{2}{*}{ COD } & \multicolumn{6}{|l|}{$3870(\mathrm{O} 2 / \mathrm{L})$} \\
\hline & & & $\begin{array}{l}\text { Specific exergy } \\
(\mathrm{kJ} / \mathrm{mg})\end{array}$ & $\begin{array}{l}\text { Exergy } \\
(\mathrm{kJ} / \mathrm{kg})\end{array}$ & & \\
\hline Method 1 & $\mathrm{CH}_{2} \mathrm{O}$ & & $1.73 \mathrm{E}-02$ & 66.8 & & \\
\hline Method 2 & $\mathrm{C}_{39} \mathrm{H}_{80} \mathrm{O}_{3}$ & & $4.22 \mathrm{E}-02$ & 54.4 & & \\
\hline Method 3 & $13.6 \times \mathrm{COD}$ & & N/A & 52.6 & & \\
\hline
\end{tabular}

N/A not applicable

A study by McCarty et al. [52] investigated the conditions in which wastewater treatment could become a net energy producer and found that low temperatures and low organic content were the main barriers to this objective. By considering a typical hypothetical AD process, McCarty et al. [52] concluded that with a COD value of at least $500 \mathrm{mg} / \mathrm{l}$, a water treatment process could result in a net positive energy production. The COD of the sample food process effluent in this case study is $3870 \mathrm{mg} / \mathrm{l}$ at a temperature of $28.9^{\circ} \mathrm{C}$, making it well suited for the $\mathrm{AD}$ process. The typical $\mathrm{AD}$ process considered by McCarty et al. [52] used an anaerobic fluidized bed bioreactor (AFMBR) with a reactor retention time of $5 \mathrm{~h}$, which is also assumed in the hypothetical AD process in this case study. The total energy expenditure for such a system is typically $0.058 \mathrm{kWh} / \mathrm{m}^{3}$ with a COD removal of $99 \%$ [53]. For the weekly average effluent flow rate of $4.55 \mathrm{~kg} / \mathrm{s}$, the supply electricity required by such an $\mathrm{AD}$ process amounts to $159.6 \mathrm{kWh} /$ week. The exergy of the treated water is composed of the inorganic content (the same as before treatment) and $1 \%$ of the remaining organic compounds, resulting in a value of 2010.4 kWh/week (see Fig. 3).

\subsection{Overall impact on resource consumption}

By modelling the resources in terms of exergy, the resource consumption in the baseline case is compared with that in
Fig. 2 Comparison of the specific exergy of the food process effluent sample with other water bodies of the world (after Chen [35])

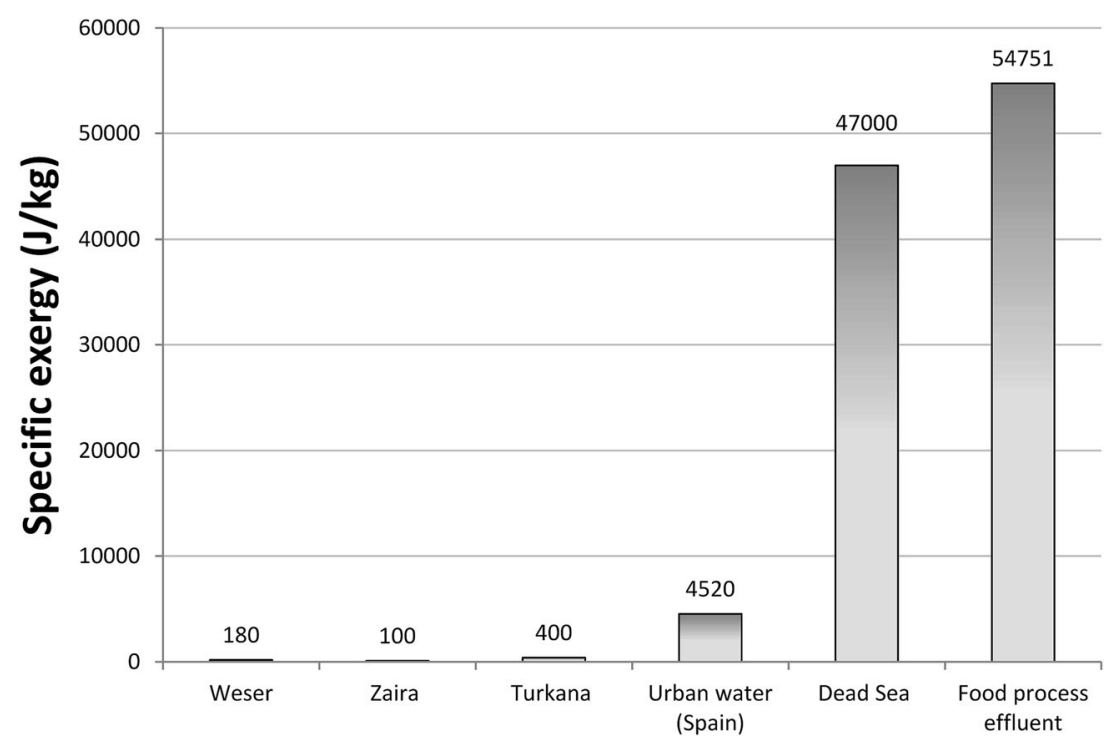




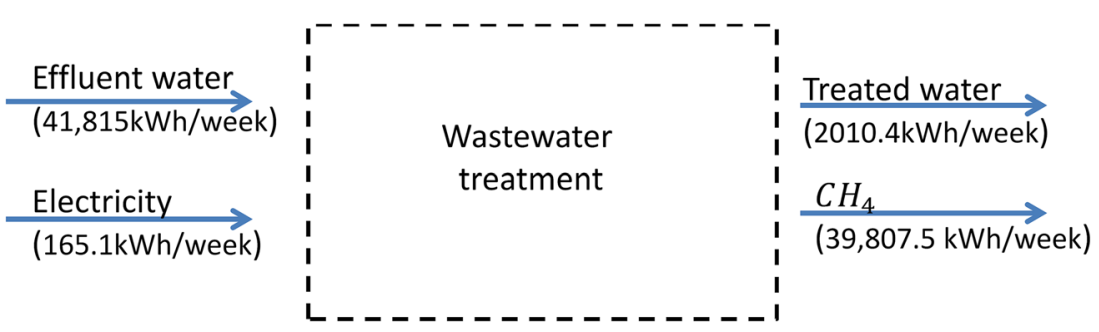

Fig. 3 Weekly averaged exergy flows through a typical AD process employed to hypothetically treat the food factory effluent

which a water treatment process featuring a hypothetical $\mathrm{AD}$ process is considered. The analysis assumes that the methane by-product from the AD process is burned to offset the gas consumption of the factory. For natural gas, the conversion factor of 1.0387 was used to convert the lower heating value to an exergy value [45]. The comparison in Table 3 shows that an overall resource saving of $4.1 \%$ could be achieved by employing an anaerobic water treatment process. Exergy supplied in the form of natural gas is reduced by $5.5 \%$ and while there is a small $(0.08 \%)$ increase in electricity consumption, there is a reduction in the overall resource demand of the factory.

\section{Discussion and conclusions}

Previous studies investigating resource accounting in factories, such as Hernandez and Cullen [15], and the methodologies on which they have been based, focused on energy and material flows with inadequate attention given to consideration of water as a valuable natural resource. It has been suggested to concurrently consider water along with energy and material in a holistic analysis of factory resource flows [6]. This article presents an exergy-based approach for the modelling of water flows in a factory. It can be considered part of a broader exergy-based methodology for resource accounting in manufacturing [54]. Moreover, exergy-based economic methods (exergoeconomics) could possibly be used to extend the scope of the methodology described in this article [55].

To the authors' knowledge, the analysis presented in this paper is the first example of manufacturing water flows explicitly being considered in terms of exergy. A food processing facility was studied, and possible resource savings achievable through water treatment were estimated. The treatment of water required electricity while generating methane gas; thus, the case study illustrates the relationship between resources of different nature, and it is an example of a study of the energy-water nexus. It is also an example of the use of exergy to enable comparison of resource consumption on a common unit basis. Some findings that highlight the strengths of the proposed methodology are described next.

Water $\left(\mathrm{m}^{3}\right)$ and energy $(\mathrm{kWh})$ supplied to the factory were compared using common units through the thermodynamic quantity exergy. This allowed an objective comparison of resource use due to flows of different nature, something not possible using energy and mass balances alone. With the assumption that the effluent composition remained constant over a weekly period, the treatment of water could result in overall resource savings of $4.1 \%$. Owing to its low average temperature $(302.95 \mathrm{~K})$, the thermal exergy was a negligible $0.03 \%$ of the total exergy in the effluent water. Due to the large mass of water flowing through the system, an energy analysis would overestimate the value of this thermal content, which could mislead decision makers.

Although the advantages of the methodology used are significant, it has limitations. The choice of reference water composition not only affects the results, but may also influence the suitability of the exergy analysis method employed. The chemical exergy of each substance present in the reference water must be calculated. Furthermore, the variety of different organic compounds that may be present necessitates the assumption of a representative organic molecule, which is a source of

Table 3 Estimation of reduction in resource use for a full-time working week in 2014 at the food factory

\begin{tabular}{lllll}
\hline & Electricity & Nat. Gas exergy & Water & Total \\
\hline & $(\mathrm{kWh} /$ week $)$ & $(\mathrm{kWh} /$ week $)$ & $(\mathrm{kWh} /$ week $)$ & $(\mathrm{kWh} /$ week $)$ \\
Baseline - No treatment & 204,434 & 766,478 & 40,605 & $1,011,517$ \\
Option 1-AD treatment & $204,434+165.1=204,599.1$ & $=766,479-41,815=724,664$ & 40,605 & 969,869 \\
Reduction in resource use & $-0.08 \%$ & $5.5 \%$ & $0 \%$ & $4.1 \%{ }^{*}$ \\
\hline
\end{tabular}

* This value is based on the assumption that the effluent composition remained constant over a weekly period 
inaccuracy in the analysis. Finally, the exergy content of a water flow gives no indication of its toxicity, an issue that is well known from previous studies [28, 33]. This limits the use of this approach for resource accounting and makes it inadequate for analysis of environmental impact.

The limitations of the methodology described in this paper suggest that it should be used with care; nevertheless, its strengths make it a useful tool for resource accounting in factories. Considering a factory to be composed of various components that interact dynamically, and through which a heterogeneous array of resources flow, the ability to compare different improvement options using a common unit basis provides significant benefits to decision makers. Furthermore, exergybased modelling of resource flows is not restricted to a particular industry. It is applicable to manufacturing in general and may also be applied at society level [56]. For this reason, exergy-informed energy management standards may be developed to be used as guidelines to facilitate practical resource efficiency in manufacturing. Considering the crux of the holistic approach is to simultaneously consider all types of resource flows in a factory, perhaps computer simulation that incorporates this methodology could be pursued as future work. The resulting simulation tool might assist factory managers to make decisions regarding resource conservation interventions while taking into account the energy-material-water nexus.

Acknowledgements This work was supported by the project REEMAIN (Resource and Energy Efficient Manufacturing). It received funding from the European Union's Seventh Programme for research, technological development and demonstration under grant agreement No 608977.

Open Access This article is distributed under the terms of the Creative Commons Attribution 4.0 International License (http:// creativecommons.org/licenses/by/4.0/), which permits unrestricted use, distribution, and reproduction in any medium, provided you give appropriate credit to the original author(s) and the source, provide a link to the Creative Commons license, and indicate if changes were made.

\section{References}

1. Chen D, Thiede S, Schudeleit T, Herrmann C (2014) A holistic and rapid sustainability assessment tool for manufacturing SMEs. CIRP Ann, Technol

2. Duflou JR, Sutherland JW, Dornfeld D, Herrmann C, Jeswiet J, Kara S, Hauschild M, Kellens K (2012) Towards energy and resource efficient manufacturing: a processes and systems approach. CIRP Ann - Manuf Technol 61:587-609

3. Thiede, S.; Schönemann, M.; Kurle, D.; Herrmann, C. Multi-level simulation in manufacturing companies: The water-energy nexus case. J Clean Prod 2016, 139

4. Schlüter BA, Rosano MB (2016) A holistic approach to energy efficiency assessment in plastic processing. J Clean Prod 118:19-28

5. Dimitriou, A. A.; Dorn, C.; Bleicher, F. a Holistic Approach for Energy Efficient Production Facilities. Ann. DAAAM Proc. 2011, $1437-1438$
6. Despeisse M, Ball PD, Evans S, Levers A (2012) Industrial ecology at factory level - a conceptual model. J Clean Prod 31:30-39

7. Rosen, M. A. A holistic approach to sustainable development of energy, water and environment systems. 2017

8. IEA Water for Energy: Is energy becoming a thirstier resource? World Energy. Outlook 2012, 1-33

9. Serrano A, Guan D, Duarte R, Paavola J (2016) Virtual water flows in the EU27: a consumption-based approach. J Ind Ecol 20:547558

10. Water in the West Water Energy Nexus: Literature Review. Inst. Sustain. Futur. ... 2013, 146

11. Chisti Y (1806-1815) Modern systems of plant cleaning. Encycl food Microbiol 1999

12. Chua KJ, Chou SK, Yang WM (2010) Advances in heat pump systems: a review. Appl Energy 87:3611-3624

13. Lowry, D. Advances in cleaning and sanitation. Aust. J. dairy Technol. 2010, 65, vi, 151

14. Mousavi S, Kara S, Kornfeld B (2016) A hierarchical framework for concurrent assessment of energy and water efficiency in manufacturing systems. J Clean Prod 133:88-98

15. Hernandez AG, Cullen JM (2016) Unlocking plant-level resource efficiency options: a unified exergy measure. Procedia CIRP 48: $122-127$

16. Leung Pah Hang, M. Y.; Martinez-Hernandez, E.; Leach, M.; Yang, A. Designing integrated local production systems: a study on the food-energy-water nexus. J. Clean. Prod. 2016, 135, 1065-1084

17. García, I.; Raslan, R.; Ruyssevelt, P. Parametric study and simulation-based exergy optimization for energy retrofits in buildings. 28TH Int. Conf. Effic. Cost, Optim. Simul. Environ. Impact. Energy Syst. 2015

18. Granovskii, M.; Dincer, I.; Rosen, M. a Exergy and industrial ecology: an application to an integrated energy system. Int. J. exergy 2008, 5, 52-63

19. Dincer I, Rosen MA (2012) Exergy: energy, environment and sustainable development. Newnes

20. Khattak S, Brown N, Greenough RM (2012) Suitability of exergy analysis for industrial energy efficiency, manufacturing and energy management. In; European Council for an Energy Efficient Economy

21. Nguyen, T.; Elmegaard, B.; Jensen, J. K.; Elmegaard, B. Energy, Exergy and Advanced Exergy Analysis of a Milk Processing Factory 2016, 1-13

22. Mojarab Soufiyan M, Dadak A, Hosseini SS, Nasiri F, Dowlati M, Tahmasebi M, Aghbashlo M (2016) Comprehensive exergy analysis of a commercial tomato paste plant with a double-effect evaporator. Energy 111:910-922

23. Jokandan MJ, Aghbashlo M, Mohtasebi SS (2015) Comprehensive exergy analysis of an industrial-scale yogurt production plant. Energy 93:1832-1851

24. Zisopoulos FK, Moejes SN, Rossier-Miranda FJ, Van Der Goot AJ, Boom RM (2015) Exergetic comparison of food waste valorization in industrial bread production. Energy 82:640-649

25. Zisopoulos FK, Rossier-Miranda FJ, Van Der Goot AJ, Boom RM (2015) The use of exergetic indicators in the food industry - a review. Crit Rev Food Sci Nutr 8398:00-00

26. Boroum and Jazi, G.; Rismanchi, B.; Saidur, R. A review on exergy analysis of industrial sector. Renew. Sustain. Energy Rev. 2013, 27, 198-203

27. Alta, Z. D.; Ertek İn, C.; Machinery, F.; Agricultural, F. A review on exergy analysis of food production processes 2014, 6-10

28. Hellström D (1997) An exergy analysis for a wastewater treatment plant: an estimation of the consumption of physical resources. Water Environ Res:44-51

29. Balkema AJ, Preisig HA, Otterpohl R, Lambert FJD (2002) Indicators for the sustainability assessment of wastewater treatment systems. Urban water 4:153-161 
30. Ayres, R. U.; Ayres, L. W.; Martina, K. Exergy, waste accounting, and life-cycle analysis 1998, 23, 355-363

31. Ao Y, Gunnewiek L, Rosen MA (2008) Critical review of exergybased indicators for the environmental impact of emissions. Int $\mathrm{J}$ Green Energy 5:87-104

32. Gaudreau K, Fraser RA, Murphy S (2009) The tenuous use of exergy as a measure of resource value or waste impact. Sustainability 1:1444-1463

33. Mora CH, Oliveira S (2006) Environmental exergy analysis of wastewater treatment plants. Therm Eng 5:24-29

34. Seckin C, Bayulken AR (2013) Extended exergy accounting (EEA) analysis of municipal wastewater treatment-determination of environmental remediation cost for municipal wastewater. Appl Energy 110:55-64

35. Chen GQ, Ji X (2007) Chemical exergy based evaluation of water quality. Ecol Model 200:259-268

36. Martínez, a.; Uche, J.; Valero, a.; Valero-Delgado, a. Environmental costs of a river watershed within the European water framework directive: Results from physical hydronomics. Energy 2010, 35, 1008-1016

37. Szargut J, Valero A, Stanek W, Valero A (2005) Towards an international legal reference environment. Proc ECOS 2005:409-420

38. Valero, A.; Uche, J.; Mart??nez, A The hidden value of water flows: The chemical exergy of rivers Int $J$ Thermodyn 2012, 15, 17-25

39. Martínez A, Uche J (2010) Chemical exergy assessment of organic matter in a water flow. Energy 35:77-84

40. Gundersen T (2009) An introduction to the concept of exergy and energy quality. Dep. Energy Process Eng. Nor. Univ. Sci. Technol. Trondheim, Norway, Version 3

41. Armando, G.-M.; Zaleta, A. A.; Hugo, R. H. V On an exergy efficiency definition of a wastewater treatment plant. Int $\mathrm{J}$ Thermodyn 2003, 6, 169-176

42. Lide, D. R. Standard thermodynamic properties of chemical substances. CRC. Handb. Chem Phys 2007, 5
43. Tai S, Matsushige K, Goda T (1986) Chemical exergy of organic matter in wastewater. Int J Environ Stud 27:301-315

44. Szargut, J.; Valero, A.; Stanek, W.; Valero, A. Towards an international reference environment of chemical exergy. Elsevier Sci. 2005, Preprint

45. CIRCE Exergoecology Portal http://www.exergoecology.com/ (accessed Oct 21, 2015)

46. Zaleta-Aguilar A, Ranz L, Valero A (1998) Towards a unified measure of renewable resources availability: the exergy method applied to the water of a river. Energy Convers Manag 39:1911-1917

47. Rivero, R. Ã.; Garfias, M. Standard chemical exergy of elements updated 2006, 31, 3310-3326

48. Chen B, Chen GQ, Hao FH, Yang ZF (2009) The water resources assessment based on resource exergy for the mainstream Yellow River. Commun Nonlinear Sci Numer Simul 14:331-344

49. Valero, A.; Uche, J.; Martínez, A. The Hidden Value of Water Flows : The Chemical Exergy of Rivers *. 2012, 15, 17-25

50. Services, S. S. Staffordshire Scientific services http://staffsscientific-services.org/ (accessed Jun 15, 2015)

51. Water, S. T. Water quality summary report; East Leicestershire Rural, 2015

52. McCarty PL, Bae J, Kim J (2011) Domestic wastewater treatment as a net energy producer - can this be achieved? Environ. Sci. Technol. 45:7100-7106

53. Kim J, Kim K, Ye H, Lee E, Shin C, McCarty PL, Bae J (2010) Anaerobic fluidized bed membrane bioreactor for wastewater treatment. Environ Sci Technol 45:576-581

54. Khattak SH, Greenough R, Korolija I, Brown N (2016) An exergy based approach to resource accounting for factories. J Clean Prod 121:99-108

55. Rosen, M. a A Concise Review of Exergy-Based Economic Methods. Int. Conf. Energy Environ. 2008, 9

56. Sousa, T.; Brockway, P. E.; Cullen, J. M.; Miller, J.; Cabrera, A.; Domingos, T. The need for robust, Consistent Methods in Societal Exergy Accounting 2017, 141, 11-21 